\title{
Article \\ Mass Spectrometric Evaluation of $\beta$-Cyclodextrins as Potential Hosts for Titanocene Dichloride
}

\author{
Pia S. Bruni (D) and Stefan Schürch *
}

check for updates

Citation: Bruni, P.S.; Schürch, S. Mass Spectrometric Evaluation of $\beta$-Cyclodextrins as Potential Hosts for Titanocene Dichloride. Int. J. Mol. Sci. 2021, 22, 9789. https://doi.org/ $10.3390 /$ ijms 22189789

Academic Editor: Alexander O. Chizhov

Received: 3 August 2021

Accepted: 6 September 2021

Published: 10 September 2021

Publisher's Note: MDPI stays neutral with regard to jurisdictional claims in published maps and institutional affiliations.

Copyright: (c) 2021 by the authors. Licensee MDPI, Basel, Switzerland. This article is an open access article distributed under the terms and conditions of the Creative Commons Attribution (CC BY) license (https:/ / creativecommons.org/licenses/by/ $4.0 /)$.
Department of Chemistry, Biochemistry and Pharmaceutical Sciences, University of Bern, 3012 Bern, Switzerland; pia.bruni@unibe.ch

* Correspondence: stefan.schuerch@unibe.ch

\begin{abstract}
Bent metallocene dichlorides $\left(\mathrm{Cp}_{2} \mathrm{MCl}_{2}, \mathrm{M}=\mathrm{Ti}, \mathrm{Mo}, \mathrm{Nb}, \ldots\right)$ have found interest as anti-cancer drugs in order to overcome the drawbacks associated with platinum-based therapeutics. However, they suffer from poor hydrolytic stability at physiological $\mathrm{pH}$. A promising approach to improve their hydrolytic stability is the formation of host-guest complexes with macrocyclic structures, such as cyclodextrins. In this work, we utilized nanoelectrospray ionization tandem mass spectrometry to probe the interaction of titanocene dichloride with $\beta$-cyclodextrin. Unlike the non-covalent binding of phenylalanine and oxaliplatin to $\beta$-cyclodextrin, the mixture of titanocene and $\beta$-cyclodextrin led to signals assigned as $\left[\beta C D+C \mathrm{p}_{2} \mathrm{Ti}-\mathrm{H}\right]^{+}$, indicating a covalent character of the interaction. This finding is supported by titanated cyclodextrin fragment ions occurring from collisional activation. Employing di- and trimethylated $\beta$-cyclodextrins as hosts enabled the elucidation of the influence of the cyclodextrin hydroxy groups on the interaction with guest structures. Masking of the hydroxy groups was found to impair the covalent interaction and enabling the encapsulation of the guest structure within the hydrophobic cavity of the cyclodextrin. Findings are further supported by breakdown curves obtained by gas-phase dissociation of the various complexes.
\end{abstract}

Keywords: metallocene; gas-phase reaction; cyclodextrin; mass spectrometry; host-guest complex

\section{Introduction}

Good solubility and stability in a physiological aqueous environment are essential prerequisites of a pharmaceutically active compound in order to develop its therapeutic activity. Within this context, low bioavailability due to high hydrophobicity, fast degradation, or deactivation as a result of rapid reaction with unspecific targets represent a continuous challenge in drug formulation [1,2]. Organometallic anti-cancer drugs based on transition metal complexes, such as cisplatin and its analogs and bent metallocene complexes, which are known to target nucleic acids as well as proteins, are severely suffering these difficulties [3].

Cisplatin exhibits a planar structure with a platinum(II) coordination center surrounded by two ammine and two chloride ligands in cis configuration (Figure 1) [4]. It is widely used in cancer treatment but suffers from severe side-effects due to its toxicity and accruing drug resistance [5]. By alteration of the ligands, alternative drugs (e.g., carboplatin, oxaliplatin) were developed to overcome these drawbacks [4]. In addition, transition metal centered bent metallocenes emerged as a promising alternative to platinum-based drugs [5].

\subsection{Bent Metallocenes}

Bent metallocene dichlorides $\left(\mathrm{Cp}_{2} \mathrm{MCl}_{2}\right)$ are built of a transition metal center $\mathrm{M}$, often $\mathrm{Ti}, \mathrm{Mo}, \mathrm{Nb}$, or $\mathrm{V}$, two $\eta^{5}$-cyclopentadienyl ligands $(\mathrm{Cp})$ and two chloride ligands (Figure 1) $[3,6,7]$. In contrast to the platinum-based compounds, the transition metal is generally in the +IV oxidation state, and the overall structure resembles a distorted tetrahedron [6]. Among these metallocenes, titanocene had entered clinical trials in the 1990s, but 
was finally rejected due to insufficient response to metastatic cancers [8,9]. Nevertheless, the proven antiproliferative activity of metallocenes encourages further investigation of their interaction with potential biological targets.

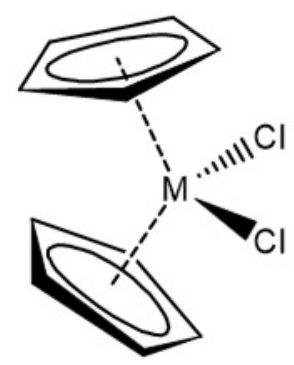<smiles>N[P+](N)(Cl)Cl</smiles>

$\mathrm{M}=\mathrm{Ti}, \mathrm{V}, \mathrm{Nb}, \mathrm{Mo}, \mathrm{Hf}$,<smiles>N[C@@H]1CCCC[C@H]1N</smiles>

Figure 1. Structure of bent metallocene dichlorides $(\mathrm{M}=\mathrm{Ti}, \mathrm{V}, \mathrm{Nb}, \mathrm{Mo}, \mathrm{Hf}, \ldots)$, cisplatin, and its derivative oxaliplatin.

A key step for the development of the anti-cancer activity of these compounds is the exchange of the chloride ligands for hydroxy ions in an aqueous environment $[4,10]$. Hydrolysis of the first chloride ligand occurs rapidly, whereas the exchange of the second chloride ligand is dependent on the metal species and the $\mathrm{pH}$ of the solution. For titanocene dichloride, the half-life of the second chloride ligand is $\sim 50 \mathrm{~min}$ [11]. In consequence of this hydrolysis, the $\mathrm{pH}$ of the solution drops significantly, resulting in substantial difficulties in the application in biological systems due to increased side effects [6]. In the case of titanocene, raising the $\mathrm{pH}$ to physiological conditions leads to hydrolysis of the two $\mathrm{Cp}$-ligands and the formation of insoluble titanium oxide species [6,7,12]. In contrast, molybdenocene shows increased hydrolytic stability of the Cp-ligands at higher $\mathrm{pH}[3,13]$. Although some metallocene dichlorides exhibit higher stability than others, their aqueous stability is generally poor and represents a major challenge for their administration and necessitates the processing of the drug prior to usage [5,7]. One approach is the replacement of one or both chloride ligands by different halogenides or organic ligands $[6,14,15]$, while other studies aimed at a more targeted drug delivery by functionalization of the $\mathrm{Cp}$-ligands (e.g., titanocene $\mathrm{Y}$ ) or alteration of the metal center [5-7,14-18].

Another approach to prevent metallocenes from extensive hydrolysis in an aqueous environment is the encapsulation within a host molecule [12,19]. Additional advantages of this approach are the increased aqueous solubility and bioavailability and a lowered toxicity $[1,4,12,13,15,20,21]$. Host molecules typically combine a rather hydrophobic inner cavity, which undergoes non-covalent interaction with the guest molecules (or parts of it) with a more polar outer surface that promotes better solubility in an aqueous environment $[1,22,23]$. Examples of host molecules successfully applied in drug delivery are cyclodextrins, cucurbiturils, pillarenes, and calixarenes [24,25].

\subsection{Cyclodextrins as Host Molecules}

Due to their low toxicity $[1,23,26]$, cyclodextrins are considered safe excipients when administered orally. In addition, they have found widespread applications as hosts of poorly soluble therapeutic agents, as summarized in recent review articles [2,22,23,26,27]. Cyclodextrins are a family of cyclic oligosaccharides composed of $(1,4)$-linked $\alpha$-D-glucopyranose units. The naturally occurring $\alpha-, \beta-$, and $\gamma$-cyclodextrins, comprising 6,7 , or 8 subunits, respectively, 
are the result of the enzymatic degradation of starch. Due to the chair conformation of the glucopyranose monomer, cyclodextrins adopt the shape of a truncated cone, with the hydroxy groups located at the rim and the skeletal carbon atoms providing the hydrophobic character of the cavity (Figure 2) $[1,2,22,23,26-30]$. The ability to form a host-guest system depends on various factors. The size of the cavity of the host molecule has to fit the size of the guest structure. In the case of bent metallocenes, the cavity size of $\beta$-cyclodextrin (6.0-6.5 $)$ is suitable for accommodating the $\mathrm{Cp}$-ligands of titanocene dichloride with a diameter of $5.8 \AA[1,22,24]$. The driving forces of the interaction between the host and guest structures include hydrophobic interactions, electrostatic, van der Waals, as well as hydrogen bonding $[1,2,25,30,31]$. A key criterion that defines host-guest complexes is that no covalent bonds are broken nor newly formed $[22,23,25,26]$. Consequently, the host-guest complex is in equilibrium with the free cyclodextrin and its guest molecules in solution $[23,26,27]$.

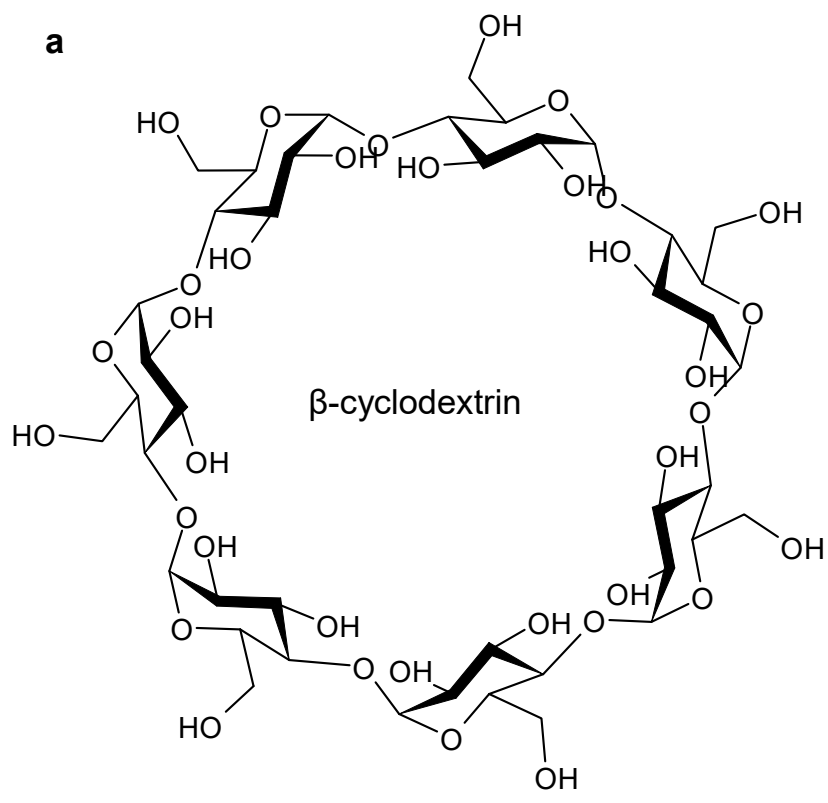

b

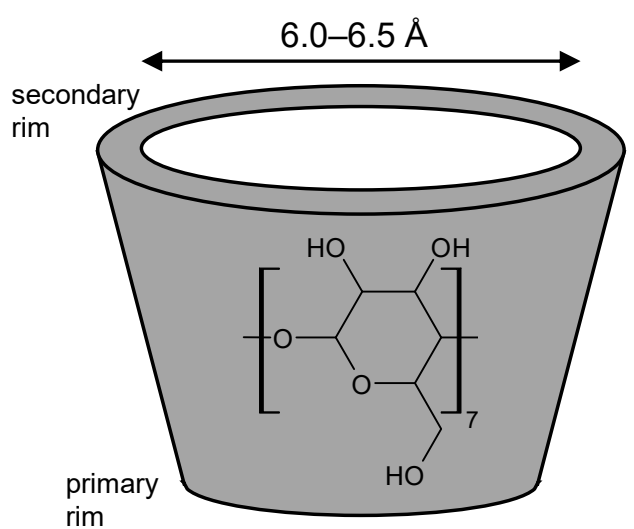

Figure 2. (a) Structural formula of $\beta$-cyclodextrin; (b) sketch of the truncated cone formed by $\beta$-cyclodextrin with the size of the cavity.

The formation of hydrogen bonds between adjacent hydroxy groups at the rim of cyclodextrins leads to a rather rigid structure and lowers their solubility, as the interaction with the surrounding water is decreased [22]. By modification of the hydroxy groups, e.g., by conversion into methyl-, hydroxypropyl-, sulfobutyl ether-, or acetyl-moieties, the regular hydrogen-bonding within the natural cyclodextrins is disrupted, thus, enabling better interaction with the surrounding water molecules and increasing the solubility $[2,22,26,27]$.

\subsection{Investigation of Complexes}

Common techniques used to investigate the stability of cyclodextrin-substrate complexes are calorimetric analysis, nuclear magnetic resonance spectroscopy (NMR), X-ray diffraction, fluorescence spectroscopy, and FTIR. Phase solubility studies and conductometry titration are alternative methods suitable for the investigation of the efficiency of cyclodextrin complexation $[2,13,26,31,32]$. Furthermore, theoretical approaches and computational modeling have been applied to predict the structure of complexes $[4,33]$.

Using these methods, the encapsulation of organic molecules including amino acids $[2,31,34]$ and platinum compounds $[4,35]$ has been described, and evidence for the inclusion of bent metallocenes with confirmed antitumor activity $(\mathrm{M}=\mathrm{Ti}, \mathrm{Mo}, \mathrm{Nb}, \mathrm{V})$ in cyclodextrins was provided by various authors $[12,13,15,29,33,36-39]$. Depending on the metallocene, its orientation and hydrolysis state for encapsulation was found to be different. Based on an experimental and theoretical study, Braga et al. suggested molybdenocene dichloride entering the $\beta$-cyclodextrin cavity 
preferably with only one Cp-ligand [33], whereas Morales et al. proposed niobocene to be incorporated as $\mathrm{Cp}_{2} \mathrm{NbCl}_{2} \mathrm{OH}$, with the inclusion of one or both $\mathrm{Cp}$-ligands occurring [12]. Theoretical considerations by Rivis et al. led to the conclusion that the formation of titanocene/cyclodextrin inclusion compounds is feasible and enhances the cytotoxic activity of titanocene as it enables controlled release of the drug and diminishes the hydrolysis of ligands [19].

\subsection{Mass Spectrometry}

Although inclusion complexes with cyclodextrins have been studied using various techniques, mass spectrometry contributed only rarely. With soft-ionization techniques such as matrix-assisted laser desorption/ionization and electrospray ionization, mass spectrometry has become a useful tool for the elucidation of molecular weights, stoichiometries, and even non-covalent interactions within supramolecular assemblies $[25,32,34,39,40]$. Mass spectrometry may provide advantages over different analytical techniques in terms of sensitivity and speed [32], and tandem mass spectrometric experiments employing collisional activation have successfully been applied to the evaluation of the relative stabilities of host-guest complexes [25]. The technique has been applied to provide information on the encapsulation of organic structures [25,34,41], ferrocene and its derivatives [39], as well as bent metallocenes [38] in cyclodextrins.

Mass spectrometric data on the inclusion of bent metallocenes have been published only sparsely. The scope of this investigation is to provide further insight into the interaction of titanocene dichloride with $\beta$-cyclodextrin and methylated cyclodextrin derivatives to assess the potential of these carbohydrate macrocycles as excipients in the formulation of bent metallocene-based drugs.

\section{Results}

Despite electrospray being a soft ionization technique, the decomposition of analyte ions due to collision with residual gas in the interface region may occur and potentially compromise the results. To probe the extent of such interfering effects and to demonstrate the capability of mass spectrometry to visualize host-guest interactions of cyclodextrin with organic compounds as well as transition metal complexes, phenylalanine, and the anti-cancer agent oxaliplatin, were chosen as guests. In a second step, the study was extended to the interaction of cyclodextrin with the bent metallocene titanocene dichloride.

Initial experiments aimed at the identification of peaks originating from the individual host and guest molecules, as besides the generation of molecular ions, adduct formation and in-source decomposition were expected, resulting in rather complex mass spectra. Based on high-resolution accurate mass analysis with deviations in the low parts per million (ppm) range and the detected isotopic pattern, the elemental composition of molecular as well as fragment ions can be determined. The full scan mass spectrum of $\beta$-cyclodextrin shows the protonated species $\left[\beta C D+\mathrm{H}^{+}(m / z\right.$ 1135.3798, $2.5 \mathrm{ppm})$, the ammonium adduct $\left[\beta C D+\mathrm{NH}_{4}\right]^{+}(m / z 1152.4060,2.1 \mathrm{ppm})$, and the alkali metal-adducts $[\beta \mathrm{CD}+\mathrm{Na}]^{+}$ $(m / z 1157.3599,0.8 \mathrm{ppm})$ and $[\beta C D+\mathrm{K}]^{+}(m / z 1173.3340,0.9 \mathrm{ppm})$. Furthermore, in-source fragmentation products due to the loss of glucopyranose subunits [glc $\left.c_{n}+\mathrm{H}\right]^{+}(\mathrm{n}=2-6$; $m / z 325.1128,-0.3 \mathrm{ppm} ; m / z$ 487.1653, $-0.8 \mathrm{ppm} ; m / z$ 649.2186, $0.0 \mathrm{ppm} ; \mathrm{m} / z$ 811.2720, $0.7 \mathrm{ppm} ; m / z$ 973.3255, $1.3 \mathrm{ppm}$ ) were identified (Supplementary Materials Table S1) [42].

Electrospray ionization mass spectrometry of guest species primarily results in their protonation and the formation of the corresponding sodium adducts. Additionally, fragment ions originating from in-source decomposition were detected. In the case of phenylalanine, the protonated form $[\mathrm{Phe}+\mathrm{H}]^{+}(m / z 166.0856,-4.8 \mathrm{ppm})$, the alkali adducts $[\mathrm{Phe}+\mathrm{Na}]^{+}(m / z 188.0676,-3.2 \mathrm{ppm})$ and $\left[\mathrm{Phe}+\mathrm{K}^{+}(m / z 204.0416,-2.5 \mathrm{ppm})\right.$, as well as the immonium ion $[\mathrm{Imm}(\mathrm{Phe})]^{+}(m / z 120.0803$, $-4.2 \mathrm{ppm}$ ) were identified (Supplementary Materials Table S2). Comparable signals appeared for oxaliplatin, where [oxaliPt $+\mathrm{H}]^{+}(\mathrm{m} / z$ 395.0695, $5.3 \mathrm{ppm})$ and [oxaliPt $\left.+\mathrm{Na}\right]^{+}(\mathrm{m} / z$ 420.0514, $4.8 \mathrm{ppm}$ ) were detected (Supplementary Materials Table S3). The mass spectra of titanocene dichloride show signals corresponding to $\left[\mathrm{Cp}_{2} \mathrm{TiCl}\right]^{+}(\mathrm{m} / z 212.9940,-2.3 \mathrm{ppm})$ and the hydrolysis products $\left[\mathrm{Cp}_{2} \mathrm{Ti}(\mathrm{OH})\right]^{+}(m / z$ 195.0278, $-3.1 \mathrm{ppm}),\left[\mathrm{CpTi}(\mathrm{OH})_{2}+\mathrm{H}_{2} \mathrm{O}\right]^{+}(m / z 165.0021,-3.0 \mathrm{ppm})$, 
$\left[\mathrm{CpTi}(\mathrm{OH})_{2}\right]^{+}(m / z$ 146.9915, $-3.4 \mathrm{ppm})$, and $\left[\mathrm{Ti}(\mathrm{OH})_{3}+\mathrm{H}_{2} \mathrm{O}\right]^{+}(m / z$ 116.9657, $-4.3 \mathrm{ppm})$, as well as $\left[\mathrm{Cp}_{2} \mathrm{Ti}(\mathrm{COOH})\right]^{+}(\mathrm{m} / z$ 223.0227, $-2.7 \mathrm{ppm})$, which was formed due to the presence of formic acid (Supplementary Materials Table S4). Though the samples were subjected to mass spectrometric analysis immediately after getting in contact with water, rapid hydrolysis of the chloride ligands could not be prevented. Experiments performed in pure $\mathrm{MeOH}$ resulted in comparable peaks, with the difference that complexes comprising not only hydroxo-, but also methoxo-ligands, such as $\left[\mathrm{CpTi}(\mathrm{OH})(\mathrm{OMe})\left(\mathrm{H}_{2} \mathrm{O}\right)\right]^{+}$at $m / z 179.0178(-2.2 \mathrm{ppm})$, were detected as well (Supplementary Materials Table S5).

\subsection{Phenylalanine and Oxaliplatin Complexes}

Beside the previously described ions, analysis of mixtures of $\beta$-cyclodextrin with phenylalanine and oxaliplatin revealed signals referring to the protonated inclusion complexes $[\beta C D+$ Phe $+\mathrm{H}]^{+}(m / z$ 1300.4575, $1.2 \mathrm{ppm})$ and $[\beta C D+\text { oxaliPt }+\mathrm{H}]^{+}(m / z$ 1532.4389, $1.1 \mathrm{ppm})$, as well as the sodium adducts $[\beta C D+\mathrm{Phe}+\mathrm{Na}]^{+}(m / z 1322.4392,0.9 \mathrm{ppm})$ and $[\beta C D+\text { oxaliPt }+\mathrm{Na}]^{+}$ $(\mathrm{m} / \mathrm{z}$ 1554.4207, $1.0 \mathrm{ppm})$, respectively (Supplementary Materials Tables S6 and S8).

A higher energy collision induced dissociation (HCD) experiment with $[\beta C D+\mathrm{Phe}+\mathrm{H}]^{+}$ as the precursor ion gave rise to signals referring to protonated phenylalanine [Phe $+\mathrm{H}]^{+}$ $(\mathrm{m} / \mathrm{z} 166.0863,0.0 \mathrm{ppm})$, protonated $\beta$-cyclodextrin $[\beta C D+\mathrm{H}]^{+}(\mathrm{m} / z 1135.3777,0.6 \mathrm{ppm})$, and protonated cyclodextrin fragments [glc $\mathrm{n}+\mathrm{H}]^{+}(\mathrm{n}=1-6 ; m / z 163.0601,0.0 \mathrm{ppm} ; \mathrm{m} / z 325.1131,0.6 \mathrm{ppm}$; $m / z$ 487.1655, $-0.4 \mathrm{ppm} ; m / z$ 649.2187, $0.2 \mathrm{ppm} ; m / z$ 811.2717, $0.4 \mathrm{ppm} ; m / z$ 973.3250, $0.8 \mathrm{ppm}$ ), indicating complete separation of host and guest along with the simultaneous decomposition of the host structure (Figure 3, Supplementary Materials Table S7). Fragmentation of the oxaliplatin inclusion complex $[\beta C D+\text { oxaliPt }+\mathrm{H}]^{+}$resulted in abundant signals of protonated oxaliplatin [oxaliPt $+\mathrm{H}]^{+}(m / z 398.0681,1.8 \mathrm{ppm})$ and protonated cyclodextrin fragments still interacting with oxaliplatin $\left[\mathrm{glc}_{\mathrm{n}}+\text { oxaliPt }+\mathrm{H}\right]^{+}(\mathrm{n}=3-6 ; m / z$ 884.2279, $2.3 \mathrm{ppm} ; \mathrm{m} / z$ 1046.2812, $2.4 \mathrm{ppm}$; $m / z 1208.3344,2.4 \mathrm{ppm} ; m / z 1370.3872,2.1 \mathrm{ppm}$ ), whereas fragments of $\beta$-cyclodextrin without oxaliplatin were of very low intensity (Supplementary Materials Table S9). The molecular formula determined by accurate mass analysis of this singly charged ion hints at neutral $\beta$-cyclodextrin fragments interacting with neutral oxaliplatin in a non-covalent manner with the positive charge provided by an additional proton, whose exact location is not defined. Despite the fact that separation of the host and guest structures was not detected as for phenylalanine, the non-covalent interaction between oxaliplatin and the macrocycle indicates the formation of an inclusion complex.

\subsection{Titanocene Complex}

Analysis of a 1:1 stoichiometric mixture of $\beta$-cyclodextrin and titanocene dichloride showed the ions arising from titanocene, mainly in hydrolyzed form as $\left[\mathrm{Cp}_{2} \mathrm{Ti}(\mathrm{OH})\right]^{+}(\mathrm{m} / z$ 195.0286, $1.0 \mathrm{ppm}$ ), and from $\beta$-cyclodextrin (Figure 4, Supplementary Materials Table S10). In addition, the isotopic distribution of the ion appearing at $m / z 1311.3913$ indicates an interaction between the titanium compound and $\beta$-cyclodextrin. Based on the accurate mass determination, the elemental composition of this ion was found to be $\mathrm{C}_{52} \mathrm{H}_{79} \mathrm{O}_{35} \mathrm{Ti}^{+}$, which corresponds to $\left[\beta \mathrm{CD}+\mathrm{Cp}_{2} \mathrm{Ti}-\mathrm{H}\right]^{+}$. Since the combination of $\beta$-cyclodextrin $\left(\mathrm{C}_{42} \mathrm{H}_{70} \mathrm{O}_{35}\right)$ and $\mathrm{Cp}_{2} \mathrm{Ti}^{2+}\left(\mathrm{C}_{10} \mathrm{H}_{10} \mathrm{Ti}^{2+}\right)$ would result in a doubly charged complex with an elemental composition of $\mathrm{C}_{52} \mathrm{H}_{80} \mathrm{O}_{35} \mathrm{Ti}^{2+}$, one of the two charges must have been compensated for by the lack of a proton, presumably at a hydroxy group at either the primary or the secondary rim of $\beta$-cyclodextrin. More detailed localization of the deprotonation site, however, was not accomplishable by means of mass spectrometry. 


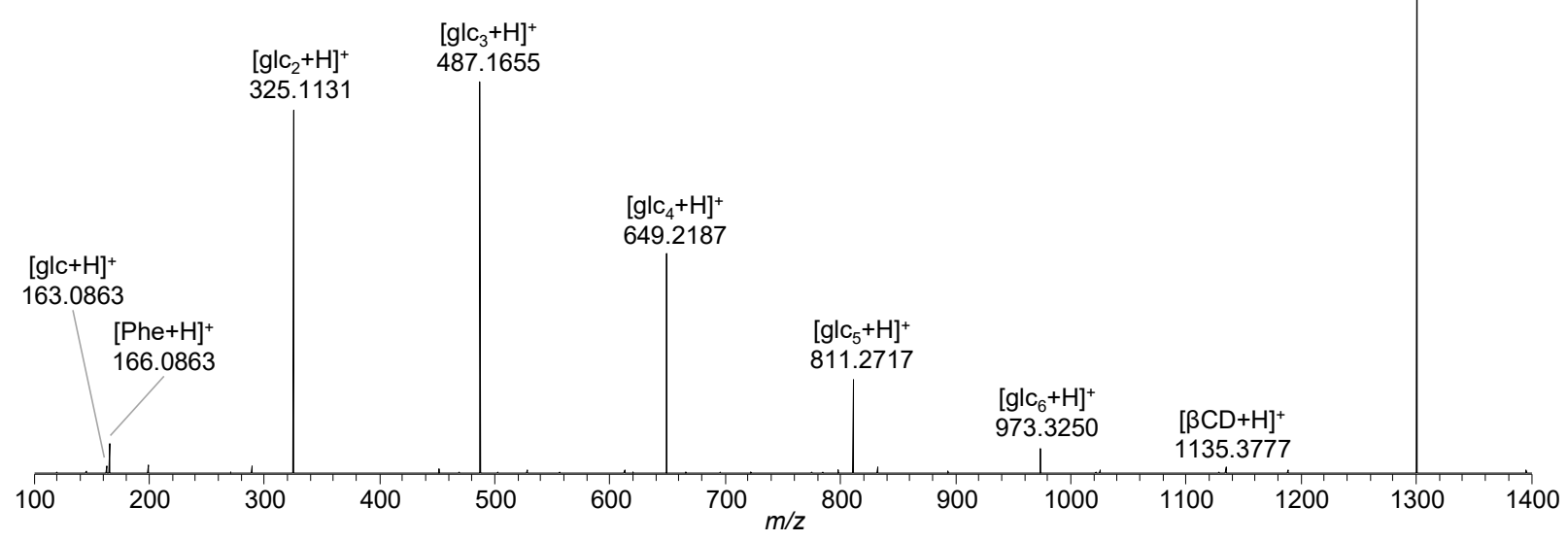

Figure 3. Higher energy collision induced dissociation (HCD) spectrum of $[\beta C D+P h e+H]^{+}(m / z 1300.48)$ at $37 \mathrm{eV}$ $\left(16 \%\right.$ normalized collision energy (NCE)) showing the separation of the precursor ion into $[\mathrm{Phe}+\mathrm{H}]^{+},[\beta C D+\mathrm{H}]^{+}$, and $\beta$-cyclodextrin fragment ions $\left[\mathrm{glc}_{\mathrm{n}}+\mathrm{H}\right]^{+}(\mathrm{n}=1-6)$.
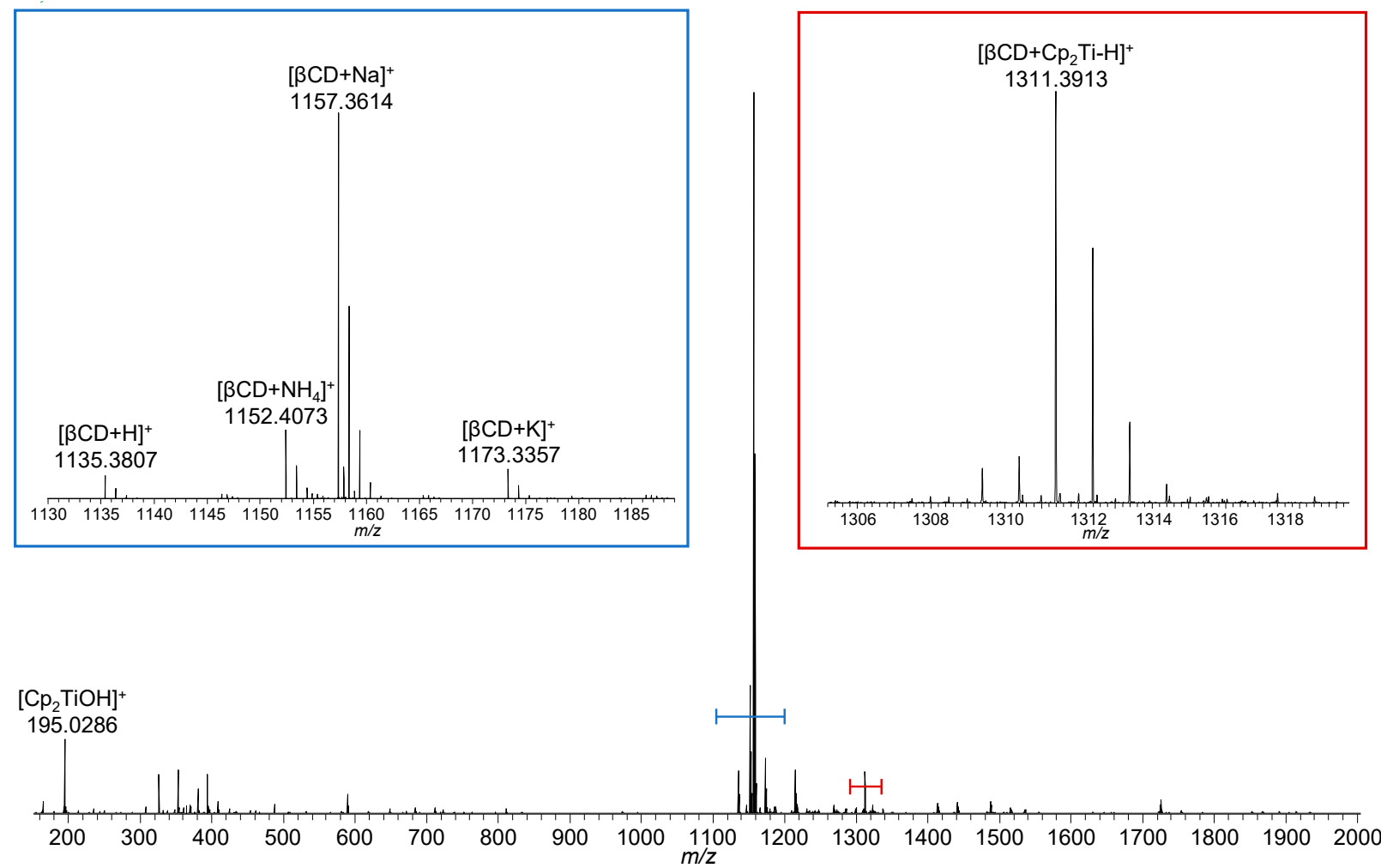

Figure 4. Full scan mass spectrum of the mixture of $\beta$-cyclodextrin and titanocene dichloride showing the peak indicating an interaction between the two compounds (red inset), as well as the hydrolyzed titanocene, and cationized $\beta$-cyclodextrin (blue). 
Collisional activation of $\left[\beta C D+\mathrm{Cp}_{2} \mathrm{Ti}-\mathrm{H}\right]^{+}(\mathrm{m} / z$ 1311.3859, $-1.3 \mathrm{ppm})$ resulted in the loss of a neutral cyclopentadiene $\left(\mathrm{C}_{5} \mathrm{H}_{6}\right)$ moiety, leading to $[\beta \mathrm{CD}+\mathrm{CpTi}-2 \mathrm{H}]^{+}$ $(\mathrm{m} / z$ 1245.3391, $-1.2 \mathrm{ppm})$. With increasing energy, the loss of neutral glucose subunits from $\beta$-cyclodextrin occurred, but the titanium species was still bound to the cyclodextrin fragment ions, as indicated by the $\left[\mathrm{glc}_{\mathrm{n}}+\mathrm{Cp}_{2} \mathrm{Ti}-\mathrm{H}\right]^{+}(\mathrm{n}=1-6 ; m / z 339.0699,-2.1 \mathrm{ppm}$; $m / z$ 501.1221, -2.8 ppm; $m / z$ 663.1747, -2.4 ppm; $m / z$ 825.2277, -1.7 ppm; $m / z$ 987.2802, $-1.7 \mathrm{ppm} ; m / z$ 1245.3391, $-1.2 \mathrm{ppm})$ and $\left[\mathrm{glc}_{\mathrm{n}}+\mathrm{CpTi}-2 \mathrm{H}\right]^{+}(\mathrm{n}=1-6 ; m / z$ 273.0233, $-1.5 \mathrm{ppm} ; \mathrm{m} / z$ 435.0754, $-2.5 \mathrm{ppm} ; \mathrm{m} / z$ 597.1281, $-2.0 \mathrm{ppm} ; \mathrm{m} / z$ 759.1808, $-1.8 \mathrm{ppm}$; $m / z$ 921.2335, $-1.6 \mathrm{ppm} ; m / z 1083.2862,-1.5 \mathrm{ppm})$ fragment ions. Loss of the second cyclopentadiene moiety in combination with the decomposition of $\beta$-cyclodextrin resulted in $\left[\mathrm{glc}_{\mathrm{n}}+\mathrm{Ti}-3 \mathrm{H}\right]^{+}(\mathrm{n}=2-6 ; m / z$ 369.0287, $-2.4 \mathrm{ppm} ; \mathrm{m} / z$ 531.0811, $-2.4 \mathrm{ppm} ; \mathrm{m} / z$ 693.1339, $-1.9 \mathrm{ppm} ; m / z$ 855.1866, $-1.6 \mathrm{ppm} ; m / z$ 1017.2391, $-1.8 \mathrm{ppm}$ ) fragment ions (Figure 5 , Supplementary Materials Table S11). In contrast to $\beta$-cyclodextrin complexes with phenylalanine and oxaliplatin, separation of the host and guest structures was not observed as neither the intact $\beta$-cyclodextrin nor free titanocene-derived ions (e.g., $\left[\mathrm{Cp}_{2} \mathrm{Ti}(\mathrm{OH})\right]^{+}$) were detected and all fragment ions were found to contain titanium. These results indicate that the interaction of titanocene dichloride with cyclodextrin differs from the situation observed for the phenylalanine and oxaliplatin guest species.

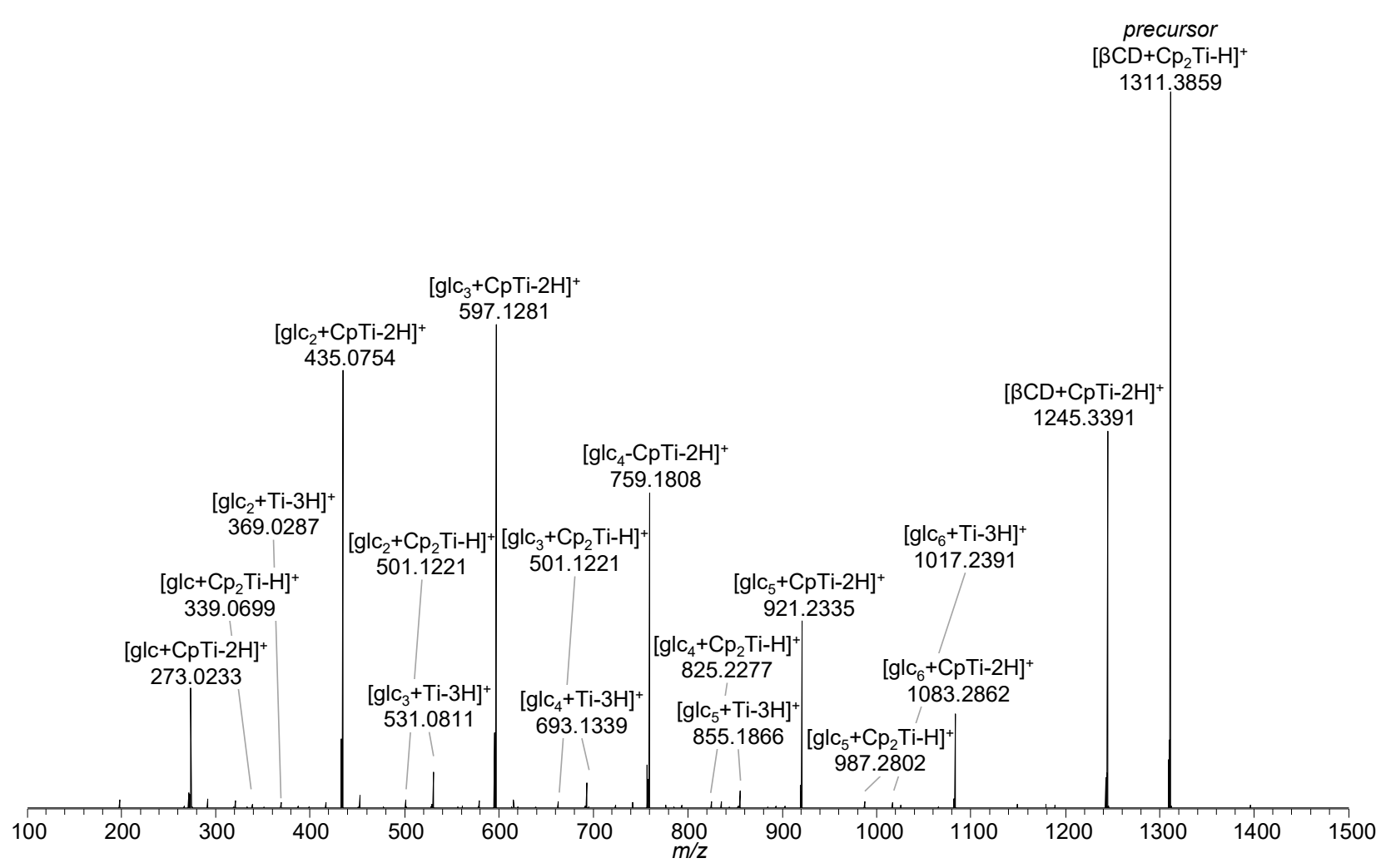

Figure 5. $\mathrm{HCD}$ mass spectrum of $\left[\beta C D+\mathrm{Cp}_{2} \mathrm{Ti}-\mathrm{H}\right]^{+}(\mathrm{m} / z$ 1311.40) at $47 \mathrm{eV}(20 \% \mathrm{NCE})$ showing the loss of one or two cyclopentadiene moieties $\left(\mathrm{C}_{5} \mathrm{H}_{6}\right)$ and the decomposition of $\beta$-cyclodextrin into its subunits, still interacting with titanocene species.

Additional experiments probing the interaction of titanocene dichloride with the disaccharides sucrose and maltose gave evidence for the formation of singly charged [sugar $\left.+\mathrm{Cp}_{2} \mathrm{Ti}-\mathrm{H}\right]^{+}$ions $(m / z 519.1314,-5.1 \mathrm{ppm}$ and $m / z$ 519.1325, -3.1 ppm; Supplementary Materials Tables S12 and S14), which is in agreement with the interaction observed for the titanocene with cyclodextrin. Collisional activation of this ion resulted in metallated fragment ions, such as $\left[\mathrm{C}_{6} \mathrm{H}_{10} \mathrm{O}_{5}+\mathrm{Cp}_{2} \mathrm{Ti}-\mathrm{H}\right]^{+}(\mathrm{m} / z 339.0696,-3.2 \mathrm{ppm})$ and $\left[\mathrm{C}_{6} \mathrm{H}_{12} \mathrm{O}_{6}+\mathrm{Cp}_{2} \mathrm{Ti}-\mathrm{H}\right]^{+}(\mathrm{m} / z$ 357.0800, $-3.4 \mathrm{ppm})$ due to glycosidic bond cleavage and loss of one of the sugar moieties as a neutral (Supplementary Materials Tables S13 and S15). 


\subsection{Methylated $\beta$-Cyclodextrins}

The di- and trimethylated cyclodextrin analogs heptakis(2,6-di-O-methyl)- $\beta$-cyclodextrin (DM $\beta$-cyclodextrin) and heptakis(2,3,6-tri-O-methyl)- $\beta$-cyclodextrin (TM $\beta$-cyclodextrin) served as host structures for probing their interaction mode with titanocene and deciphering the role of the hydroxy groups. Full scan MS analyses of the host structures showed several peaks spaced by 14 mass units, indicating different degrees of methylation. Consequently, the spectral complexity was increased and the peak intensities were significantly reduced (Supplementary Materials Tables S16 and S17) [42]. Nevertheless, the analysis of phenylalanine in the presence of the two methylated host structures revealed comparable interaction as with unmodified $\beta$-cyclodextrin, resulting in signals assigned as $[\mathrm{DM} \beta C \mathrm{CD}+\mathrm{Phe}+\mathrm{H}]^{+}(\mathrm{m} / z$ 1496.6749, $-0.1 \mathrm{ppm})$ and $[\mathrm{TM} \beta C D$ $+\mathrm{Phe}+\mathrm{H}]^{+}(m / z 1594.7865,1.1 \mathrm{ppm})$ (Supplementary Materials Tables $\mathrm{S} 18$ and S22). The masking of the hydroxy groups at the rim of $\beta$-cyclodextrin does not prevent the interaction with phenylalanine and gives proof for the ability of methylated $\beta$-cyclodextrin to act as a host for hydrophobic structures.

Collisional activation of the protonated $[\mathrm{DM} \beta \mathrm{CD}+\mathrm{Phe}+\mathrm{H}]^{+}$complexes led to fragmentation of the host structures, as demonstrated by Figure 6 for the complex with the dimethylated cyclodextrin (Supplementary Materials Table S19). Though the product ion spectrum of $[\mathrm{DM} \beta C \mathrm{CD}+\mathrm{Phe}+\mathrm{H}]^{+}$did not show the peaks of separated $[\mathrm{Phe}+\mathrm{H}]^{+}$and $[\mathrm{DM} \beta C \mathrm{CD}+\mathrm{H}]^{+}$ions, the lack of any signals referring to cyclodextrin fragments still bound to phenylalanine indicates a host-guest character of the interaction. A similar situation was encountered for trimethylated cyclodextrin as host for phenylalanine $[\mathrm{TM} \beta \mathrm{CD}+\mathrm{Phe}+\mathrm{H}]^{+}$ (Supplementary Materials Table S23).

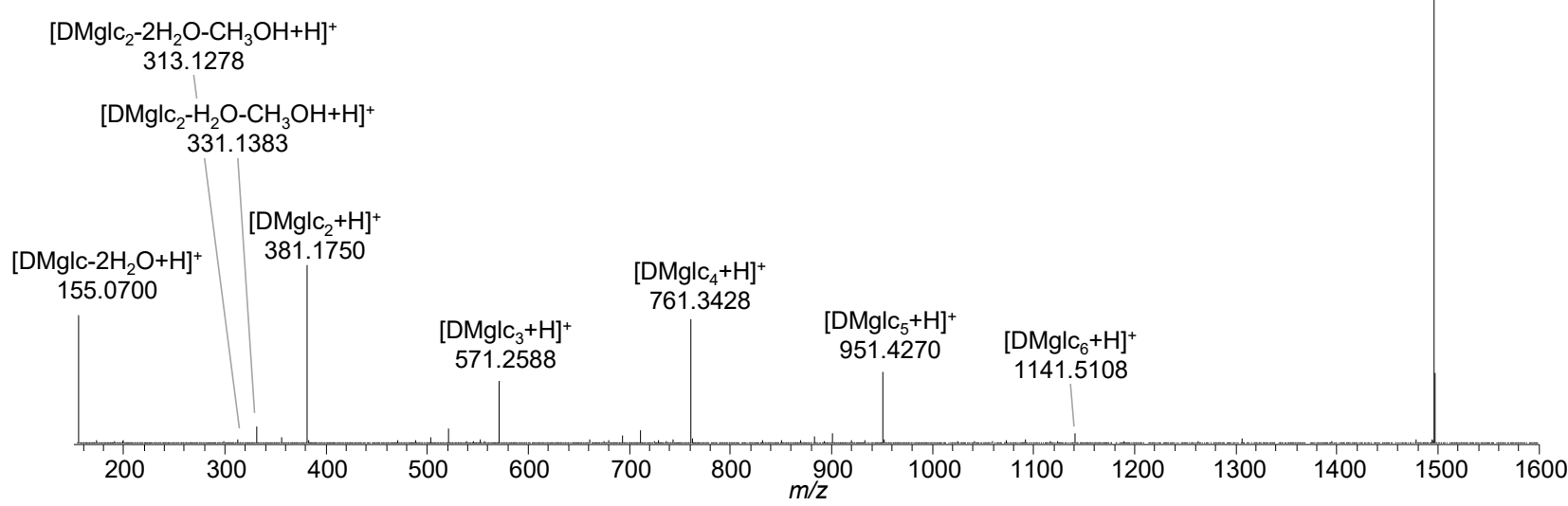

Figure 6. HCD mass spectrum of $[\mathrm{DM} \beta C \mathrm{CD}+\mathrm{Phe}+\mathrm{H}]^{+}(\mathrm{m} / z$ 1496.70) at $40 \mathrm{eV}(15 \% \mathrm{NCE})$ showing the separation of the precursor ion and subsequent decomposition of $\mathrm{DM} \beta$-cyclodextrin into its subunits $\left[\mathrm{DMgl} \mathrm{c}_{\mathrm{n}}+\mathrm{H}\right]^{+}$.

The data obtained from mixtures of titanocene with methylated cyclodextrins significantly differ from previous results on unmodified cyclodextrin. As soon as all hydroxy groups at the rim of $\beta$-cyclodextrin are methylated, as in the case of trimethylated $\beta$-cyclodextrin, a peak referring to a $\left[\mathrm{TM} \beta \mathrm{CD}+\mathrm{Cp}_{2} \mathrm{Ti}-\mathrm{H}\right]^{+}$interaction product was not observed. This is in contrast to the experiments with unmodified $\beta$-cyclodextrin, 
which revealed the peak of $\left[\beta C D+\mathrm{Cp}_{2} \mathrm{Ti}-\mathrm{H}\right]^{+}$. However, the peaks of the putative hostguest complexes $\left[\mathrm{TM} \beta \mathrm{CD}+\mathrm{Cp}_{2} \mathrm{Ti}(\mathrm{OH})_{2}+\mathrm{H}\right]^{+}(m / z$ 1641.7401, $1.6 \mathrm{ppm})$ and $[\mathrm{TM} \beta \mathrm{CD}+$ $\left.\mathrm{Cp}_{2} \mathrm{Ti}(\mathrm{OH})\right]^{+}(m / z 1623.7297,1.8 \mathrm{ppm})$ could be detected, though with minor abundance only, which hampered precursor ion isolation for tandem mass spectrometric analysis (Supplementary Materials Table S24).

A different picture was seen for dimethylated and incompletely trimethylated cyclodextrins. The analysis of the mixture of titanocene dichloride with dimethylated $\beta$-cyclodextrin resulted in signals assigned as $\left[\mathrm{DM} \beta \mathrm{CD}+\mathrm{Cp}_{2} \mathrm{Ti}-\mathrm{H}\right]^{+}(m / z 1507.6043 ;-1.6 \mathrm{ppm})$ as well as $[\mathrm{DM} \beta \mathrm{CD}$ $\left.+\mathrm{Cp}_{2} \mathrm{Ti}(\mathrm{OH})_{2}+\mathrm{H}\right]^{+}(m / z$ 1543.6249, $-1.9 \mathrm{ppm})$ (Supplementary Materials Table S20). As previously observed for the $\beta$-cyclodextrin complex, the energy provided by collisional activation of $\left[\mathrm{DM} \beta \mathrm{CD}+\mathrm{Cp}_{2} \mathrm{Ti}-\mathrm{H}\right]^{+}$promotes the loss of a Cp-ligand $\left(\mathrm{C}_{5} \mathrm{H}_{5}\right)$ yielding the $[\mathrm{DM} \beta \mathrm{CD}+\mathrm{CpTi}-$ $\mathrm{H}]^{+}(m / z 1442.5635,-2.8 \mathrm{ppm})$ fragment ion. Further fragment ions were found to correspond to titanium bound to glucose subunits, e.g., $\left[\mathrm{DMglc}_{2}+\mathrm{Cp}_{2} \mathrm{Ti}-\mathrm{H}\right]^{+}(m / z 557.1843,-3.2 \mathrm{ppm})$ (Supplementary Materials Table S21).

The hydroxy groups occurring in incompletely trimethylated $\beta$-cyclodextrins (e.g., macrocycles bearing $19\left(\mathrm{TM} \beta C D^{*}\right)$ or $20\left(\mathrm{TM} \beta C D^{\#}\right)$ instead of 21 methoxy groups only) represent targets for the interaction with titanocene. The peaks at $m / z 1577.6880$ and $m / z$ 1591.7036, corresponding to $\left[\mathrm{TM} \beta C D^{*}+\mathrm{Cp}_{2} \mathrm{Ti}-\mathrm{H}\right]^{+}(2.0 \mathrm{ppm})$ and $\left[\mathrm{TM} \beta \mathrm{CD}^{\#}+\mathrm{Cp}_{2} \mathrm{Ti}-\right.$ $\mathrm{H}]^{+}(1.9 \mathrm{ppm})$, respectively, clearly indicate that the lack of one or two methyl-groups is sufficient to form small amounts of covalently-bound titanocene adducts (Supplementary Materials Tables S23-S26).

\subsection{Breakdown Curves}

To obtain a measure for the strength of the interaction between the host and guest molecules, breakdown curves were recorded by an incremental increase of the collision energy from $0 \%$ to $50 \%$ normalized collision energy (NCE) in HCD experiments. For each identified ion, the proportion of its intensity $\left(I_{n}\right)$ in the sum of the intensities of the precursor $\left(I_{p}\right)$ and all fragment ions $\left(I_{f}\right)$ is plotted against the collision energy $\left(y_{n}=I_{n} /\left(I_{p}+\sum I_{f}\right) \cdot 100\right)[43] . \mathrm{CE}_{50}$ values (50\% of the precursor ion decomposed into fragments) of $36.2 \mathrm{eV}\left(\mathrm{E}_{\mathrm{COM}}=0.78 \mathrm{eV}\right)$ and $38.7 \mathrm{eV}\left(\mathrm{E}_{\mathrm{COM}}=0.72 \mathrm{eV}\right)$ were obtained for phenylalanine as guest in $\beta$-cyclodextrin, and for the interaction of phenylalanine with $\mathrm{DM} \beta$-cyclodextrin, respectively (Figure 7a,b, Supplementary Materials Figures S1 and S2). The $\mathrm{CE}_{50}$ value of $34.9 \mathrm{eV}\left(\mathrm{E}_{\mathrm{COM}}=0.64 \mathrm{eV}\right)$, determined for the decomposition of $[\beta C D$ + oxaliPt $+\mathrm{H}]^{+}$, is on the same scale, thus, strengthening the hypothesis of host-guest complex formation (Supplementary Materials Figure S4).

The breakdown curve of $\left[\beta C D+\mathrm{Cp}_{2} \mathrm{Ti}-\mathrm{H}\right]^{+}$shows a $\mathrm{CE}_{50}$ value of $41.3 \mathrm{eV}\left(\mathrm{E}_{\mathrm{COM}}=0.88 \mathrm{eV}\right.$, Figure 7c, Supplementary Materials Figure S3), which is significantly higher than for the hostguest complexes formed between phenylalanine and $\mathrm{DM} \beta$ - or $\beta$-cyclodextrin. Due to the loss of the first $\mathrm{Cp}$-ligand occurring at low collision energies prior to the decomposition of the cyclodextrin, the slope of the precursor decomposition curve is rather flat. 

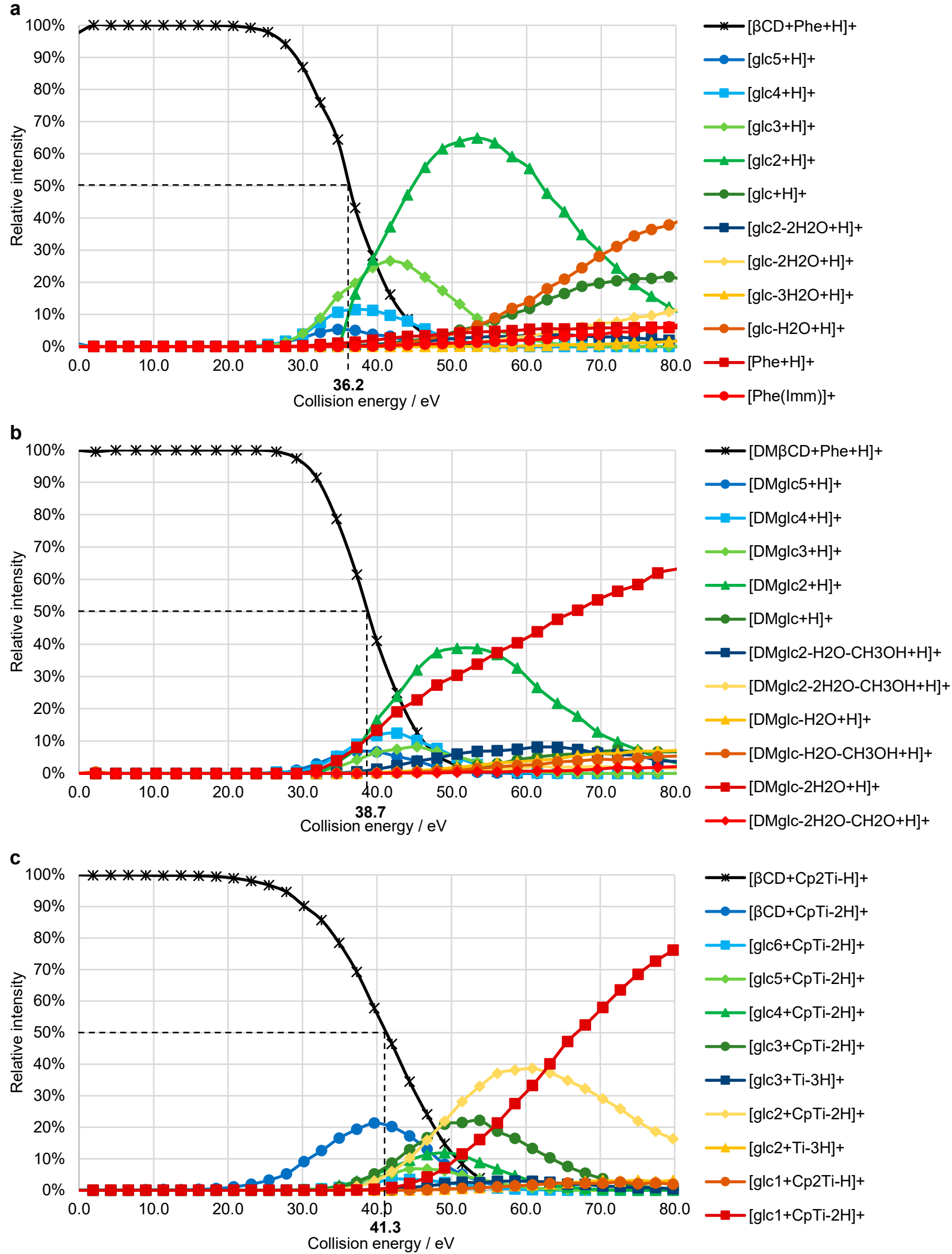

Figure 7. Breakdown curves recorded for HCD experiments of: (a) $[\beta C D+P h e+H]^{+}(m / z 1300.48)$, (b) $[\mathrm{DM} \beta \mathrm{CD}+\mathrm{Phe}+\mathrm{H}]^{+}\left(m / z\right.$ 1496.70), (c) $\left[\beta C \mathrm{CD}+\mathrm{Cp}_{2} \mathrm{Ti}-\mathrm{H}\right]^{+}(m / z$ 1311.40). Fragment ions with a maximum relative intensity $<2 \%$ are not displayed. The dashed lines indicate the $\mathrm{CE}_{50}$ values. 


\section{Discussion}

Experiments with phenylalanine and oxaliplatin demonstrated the ability of electrospray ionization mass spectrometry to detect host-guest complexes. Though the literature suggests the formation of an inclusion complex of titanocene dichloride with $\beta$-cyclodextrin $[19,38]$, mass spectrometric experiments did not give evidence for the generation of the corresponding $\left[\beta C D+\mathrm{Cp}_{2} \mathrm{TiCl}_{2}+\mathrm{H}\right]^{+}$ion at $m / z$ 1383.3409. Titanocene dichloride is known to rapidly undergo hydrolysis of the chloride ligands upon contact with water. Nevertheless, the inclusion of these hydrolysis products in $\beta$-cyclodextrin was not detected, but the corresponding peaks were observed with low abundance in the spectra with $\mathrm{DM} \beta$ - and $\mathrm{TM} \beta$-cyclodextrin hosts. On the other hand, experiments with $\beta$-cyclodextrins bearing unmodified hydroxy groups and disaccharides resulted in similar ions of the type [sugar $\left.+\mathrm{Cp}_{2} \mathrm{Ti}-\mathrm{H}\right]^{+}$, clearly indicating the significance of hydroxy groups on the interaction of titanocene with saccharides.

Based on the elemental composition determined for the titanocene-cyclodextrin assembly $\left[\beta C D+\mathrm{Cp}_{2} \mathrm{Ti}-\mathrm{H}\right]^{+}$, two interaction modes are possible: (i) formation of a single covalent bond between the titanium center and a hydroxy group of the primary or secondary rim of $\beta$-cyclodextrin with the charge residing on the titanium (Figure 8a), and (ii) formation of two covalent bonds to hydroxy groups while the charge is provided by an additional proton (Figure $8 b$ ). Elucidation of the elemental composition does not provide any further details about the mode of interaction, nor the position and number of the hydroxy groups involved. Electrospray mass spectrometric analysis of cyclodextrin, even in a mixture with the metallocene, resulted in the signal of the protonated macrocycle $(m / z 1135.3807,3.3 \mathrm{ppm})$ and additionally, in the highly abundant peak of the cyclodextrin-sodium adduct $(m / z 1157.3614$, $2.1 \mathrm{ppm})$. Sodium adduct formation $\left(\left[\beta \mathrm{CD}+\mathrm{Cp}_{2} \mathrm{Ti}-2 \mathrm{H}+\mathrm{Na}\right]^{+}, m / z\right.$ 1333.3695), however, was never observed for the titanocene-cyclodextrin assembly. In the case of interaction mode ii, this peak is anticipated, as any cation might provide the charge for the assembly. The lack of this ion suggests the formation of a single covalent bond between any deprotonated hydroxy group of $\beta$-cyclodextrin and the titanium coordination center as the most plausible mode of interaction, where the excess positive charge resides on the titanium (Figure 8a). This finding is supported by the results from collisional activation experiments of $\left[\beta C D+\mathrm{Cp}_{2} \mathrm{Ti}-\mathrm{H}\right]^{+}$, which gave evidence for cyclodextrin fragments still interacting with titanium. According to our previous work [42], bond cleavage between the glucopyranose units as the predominant mechanism for the decomposition of $\beta$-cyclodextrin is independent of the hydroxy groups and, therefore, not affected by the interaction with titanocene.

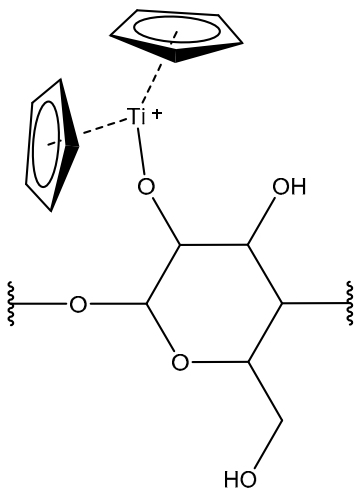

b

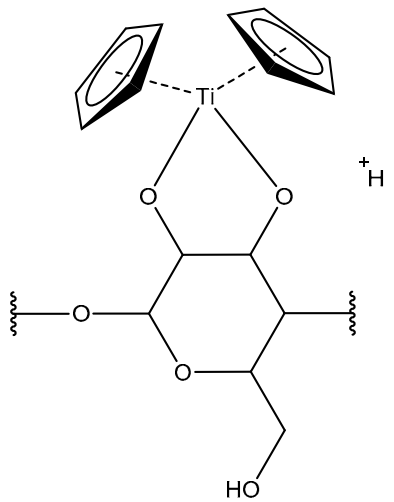

Figure 8. Possible interaction modes between titanocene and $\beta$-cyclodextrin: (a) formation of one covalent bond and the positive charge residing on the titanium; (b) formation of two covalent bonds with the charge emerging from an additional proton. 
The $\mathrm{CE}_{50}$ values determined for $[\beta \mathrm{CD}+\mathrm{Phe}+\mathrm{H}]^{+}$, $[\mathrm{DM} \beta \mathrm{CD}+\mathrm{Phe}+\mathrm{H}]^{+}$, and $\left[\beta C D+C p_{2} \mathrm{Ti}-\mathrm{H}\right]^{+}$are significantly higher than the $15.3 \mathrm{eV}$ obtained for $[\beta C D+\mathrm{H}]^{+}$in a previous study [42]. Likewise, Dossmann et al. [44] reported values ranging between 15 and $23 \mathrm{eV}$ for doubly charged metallated $\beta$-cyclodextrin ions $[\beta C D+M]^{2+}\left(\mathrm{M}=\mathrm{Fe}^{2+}\right.$, $\left.\mathrm{Co}^{2+}, \mathrm{Ni}^{2+}, \mathrm{Cu}^{2+}, \mathrm{Zn}^{2+}\right)$. At first sight, these results are unexpected as the dissociation of a covalent bond requires more energy than the disruption of a non-covalent interaction. However, a proton or metal ion bound to glycosidic oxygen significantly destabilizes the corresponding glycosidic bond, thereby inducing dissociation. Protonation of the phenylalanine inclusion complex, on the other hand, occurs most likely at the $\mathrm{N}$-terminal amino group of the amino acid, therefore not affecting the integrity of the host structure, which is reflected by the higher $\mathrm{CE}_{50}$ value.

The hypothesis of the formation of titanocene dichloride inclusion complexes with $\beta$-cyclodextrin, as previously proposed from NMR experiments [38] and theoretical approaches [19], could not be confirmed by our mass spectrometric results, as the formation of a host-guest complex without the involvement of covalent bonds would result in disintegration of the complex, as shown for the interaction of $\beta$-cyclodextrin with phenylalanine and oxaliplatin. Therefore, unmodified cyclodextrins are not expected to considerably improve the hydrolytic stability and bioavailability of titanocene dichloride.

\section{Materials and Methods}

D-L-Phenylalanine (Sigma Aldrich, Buchs, Switzerland) was dissolved in 50/50 water/acetonitrile $+0.5 \%$ formic acid (water: MilliQ, in house; acetonitrile: Biosolve, Valkenswaard, the Netherlands; formic acid: Sigma Aldrich, Buchs, Switzerland) to give a $50 \mathrm{mM}$ solution and further diluted to $1 \mathrm{mM}$ in 50/50 water/acetonitrile. Oxaliplatin and titanocene dichloride (Sigma Aldrich, Buchs, Switzerland) were dissolved in ULC-MS grade acetonitrile (Biosolve, Valkenswaard, the Netherlands) and ultrasonicated for $30 \mathrm{~min}$ to give a $1 \mathrm{mM}$ stock solution. Heptakis(2,3,6-tri-O-methyl)- $\beta$-cyclodextrin (TM $\beta$-cyclodextrin), heptakis(2,6-di-O-methyl)- $\beta$-cyclodextrin (DM $\beta$-cylclodextrin) (Sigma Aldrich, Buchs, Switzerland), $\beta$-cyclodextrin (Fluka, Sigma Aldrich, Buchs, Switzerland), sucrose (Merck, Darmstadt, Germany), and maltose (Sigma Aldrich, Buchs, Switzerland) were dissolved in MilliQ water to a final concentration of $1 \mathrm{mM}$ by shaking for $1 \mathrm{~h}$ at $21^{\circ} \mathrm{C}$ and 12,000 rpm on a thermomixer (Eppendorf, Schönenbuch, Switzerland).

For measurement, samples at a concentration of $0.02 \mathrm{mM}$ were prepared either in $50 / 50$ water/acetonitrile, 50/50 water/acetonitrile $+0.5 \%$ formic acid, or methanol (Sigma Aldrich, Bruchs, Switzerland), either of the host and guest structures solely, or mixed in a 1:1 molar ratio.

\section{Mass Spectrometry}

Nano electrospray-ionization mass spectrometric experiments were performed on an LTQ Orbitrap XL instrument (Thermo Fisher Scientific, Bremen, Germany) with Econo12 Glass PicoTips (New Objective, Littleton, MA, USA) as electrospray emitters. Mass spectrometry was performed in positive ionization mode with spray voltages ranging from 0.8 to $1.3 \mathrm{kV}$, tube lens voltage of $250 \mathrm{~V}$, capillary voltage of $20 \mathrm{~V}$, and a capillary temperature of $200{ }^{\circ} \mathrm{C}$. The mass spectrometer was used in FTMS mode at a resolution of 100,000. $\mathrm{HCD}$ experiments were performed with precursor ion isolation windows in the range of 3 to $8 \mathrm{~m} / \mathrm{z}$. Collision energies ranged between $0 \%$ and $50 \%$ NCE and were converted to $\mathrm{eV}[45,46]$. Data processing was performed using the Xcalibur software suite (Thermo Fisher Scientific, Bremen, Germany).

Supplementary Materials: Supplementary Materials can be found at https://www.mdpi.com/ article/10.3390/ijms22189789/s1.

Author Contributions: Conceptualization, methodology, project administration, validation, writingreview and editing, P.S.B. and S.S.; formal analysis, data curation, investigation, visualization, 
writing - original draft preparation, P.S.B.; resources, supervision, S.S. All authors have read and agreed to the published version of the manuscript.

Funding: This research received no external funding.

Data Availability Statement: Data are contained within the Supplementary Materials.

Conflicts of Interest: The authors declare no conflict of interest.

\section{References}

1. Gidwani, B.; Vyas, A. A Comprehensive Review on Cyclodextrin-Based Carriers for Delivery of Chemotherapeutic Cytotoxic Anticancer Drugs. Biomed. Res. Int. 2015, 2015, 198268. [CrossRef]

2. di Cagno, M. The Potential of Cyclodextrins as Novel Active Pharmaceutical Ingredients: A Short Overview. Molecules 2017, $22,1$. [CrossRef] [PubMed]

3. Waern, J.B.; Harding, M.M. Bioorganometallic Chemistry of Molybdocene Dichloride. J. Organomet. Chem. 2004, 689, 4655-4668. [CrossRef]

4. Anconi, C.P.A.; Da Silva Delgado, L.; Alves Dos Reis, J.B.; De Almeida, W.B.; Costa, L.A.S.; Dos Santos, H.F. Inclusion Complexes of $\alpha$-Cyclodextrin and the Cisplatin Analogues Oxaliplatin, Carboplatin and Nedaplatin: A Theoretical Approach. Chem. Phys. Lett. 2011, 515, 127-131. [CrossRef]

5. Causey, P.W.; Baird, M.C.; Cole, S.P.C. Synthesis, Characterization, and Assessment of Cytotoxic Properties of a Series of Titanocene Dichloride Derivatives. Organometallics 2004, 23, 4486-4494. [CrossRef]

6. Harding, M.M.; Mokdsi, G. Antitumour Metallocenes: Structure-Activity Studies and Interactions with Biomolecules. Curr. Med. Chem. 2000, 7, 1289-1303. [CrossRef] [PubMed]

7. Abeysinghe, P.M.; Harding, M.M. Antitumour Bis(Cyclopentadienyl) Metal Complexes: Titanocene and Molybdocene Dichloride and Derivatives. Dalt. Trans. 2007, 3474-3482. [CrossRef]

8. Lümmen, G.; Sperling, H.; Luboldt, H.; Otto, T.; Rübben, H. Phase II Trial of Titanocene Dichloride in Advanced Renal-Cell Carcinoma. Cancer Chemother. Pharmacol. 1998, 42, 415-417. [CrossRef]

9. Kröger, N.; Kleeberg, U.R.; Mross, K.; Edler, L.; Hossfeld, D.K. Phase II Clinical Trial of Titanocene Dichloride in Patients with Metastatic Breast Cancer. Onkologie 2000, 23, 60-62. [CrossRef]

10. Chen, X.; Zhou, L. The Hydrolysis Chemistry of Anticancer Drug Titanocene Dichloride: An Insight from Theoretical Study. J. Mol. Struct. Theochem 2010, 940, 45-49. [CrossRef]

11. Toney, J.H.; Marks, T.J. Hydrolysis Chemistry of the Metallocene Dichlorides M(H5-C5H5)2Cl2, M = Titanium, Vanadium, or Zirconium. Aqueous Kinetics, Equilibria, and Mechanistic Implications for a New Class of Antitumor Agents. J. Am. Chem. Soc. 1985, 107, 947-953. [CrossRef]

12. Morales, A.; Struppe, J.; Meléndez, E. Host-Guest Interactions between Niobocene Dichloride and $\alpha-, \beta-$, and $\gamma$-Cyclodextrins: Preparation and Characterization. J. Incl. Phenom. Macrocycl. Chem. 2008, 60, 263-270. [CrossRef]

13. Braga, S.S.; Marques, M.P.M.; Sousa, J.B.; Pillinger, M.; Teixeira-Dias, J.J.C.; Gonçalves, I.S. Inclusion of Molybdenocene Dichloride $(\mathrm{Cp} 2 \mathrm{MoCl} 2)$ in 2-Hydroxypropyl- and Trimethyl- $\beta$-Cyclodextrin: Structural and Biological Properties. J. Organomet. Chem. 2005, 690, 2905-2912. [CrossRef]

14. Meléndez, E. Metallocenes as Target Specific Drugs for Cancer Treatment. Inorganica Chim. Acta 2012, 393, 36-52. [CrossRef]

15. Meléndez, E. Bioorganometallic Chemistry of Molybdenocene Dichloride and Its Derivatives. J. Organomet. Chem. 2012, 706-707, 4-12. [CrossRef]

16. Erxleben, A.; Claffey, J.; Tacke, M. Binding and Hydrolysis Studies of Antitumoural Titanocene Dichloride and Titanocene Y with Phosphate Diesters. J. Inorg. Biochem. 2010, 104, 390-396. [CrossRef]

17. Vessières, A.; Plamont, M.-A.; Cabestaing, C.; Claffey, J.; Dieckmann, S.; Hogan, M.; Müller-Bunz, H.; Strohfeldt, K.; Tacke, M. Proliferative and Anti-Proliferative Effects of Titanium- and Iron-Based Metallocene Anti-Cancer Drugs. J. Organomet. Chem. 2009, 694, 874-879. [CrossRef]

18. Cini, M.; Bradshaw, T.D.; Woodward, S. Using Titanium Complexes to Defeat Cancer: The View from the Shoulders of Titans. Chem. Soc. Rev. 2017, 46, 1040-1051. [CrossRef]

19. Riviş, A.; Hǎdărugǎ, N.G.; Gârban, Z.; Hǎdărugǎ, D.I. Titanocene/Cyclodextrin Supramolecular Systems: A Theoretical Approach. Chem. Cent. J. 2012, 6, 129-139. [CrossRef] [PubMed]

20. Jambhekar, S.S.; Breen, P. Cyclodextrins in Pharmaceutical Formulations II: Solubilization, Binding Constant, and Complexation Efficiency. Drug Discov. Today 2016, 21, 363-368. [CrossRef] [PubMed]

21. Plumb, J.A.; Venugopal, B.; Oun, R.; Gomez-Roman, N.; Kawazoe, Y.; Venkataramanan, N.S.; Wheate, N.J. Cucurbit[7]Uril Encapsulated Cisplatin Overcomes Cisplatin Resistance via a Pharmacokinetic Effect. Metallomics 2012, 4, 561-567. [CrossRef] [PubMed]

22. Saokham, P.; Muankaew, C.; Jansook, P.; Loftsson, T. Solubility of Cyclodextrins and Drug/Cyclodextrin Complexes. Molecules 2018, 23, 1161. [CrossRef] [PubMed]

23. Jambhekar, S.S.; Breen, P. Cyclodextrins in Pharmaceutical Formulations I: Structure and Physicochemical Properties, Formation of Complexes, and Types of Complex. Drug Discov. Today 2016, 21, 356-362. [CrossRef] 
24. Senthilnathan, D.; Solomon, R.V.; Kiruthika, S.; Venuvanalingam, P.; Sundararajan, M. Are Cucurbiturils Better Drug Carriers for Bent Metallocenes? Insights from Theory. J. Biol. Inorg. Chem. 2018, 23, 413-423. [CrossRef]

25. Ramanathan, R.; Prokai, L. Electrospray Ionization Mass Spectrometric Study of Encapsulation of Amino Acids by Cyclodextrins. J. Am. Soc. Mass Spectrom. 1995, 6, 866-871. [CrossRef]

26. Jansook, P.; Ogawa, N.; Loftsson, T. Cyclodextrins: Structure, Physicochemical Properties and Pharmaceutical Applications. Int. J. Pharm. 2018, 535, 272-284. [CrossRef]

27. Davis, M.E.; Brewster, M.E. Cyclodextrin-Based Pharmaceutics: Past, Present and Future. Nat. Rev. Drug Discov. 2004, 3, 1023-1035. [CrossRef]

28. Loftsson, T.; Saokham, P.; Sá Couto, A.R. Self-Association of Cyclodextrins and Cyclodextrin Complexes in Aqueous Solutions. Int. J. Pharm. 2019, 560, 228-234. [CrossRef]

29. Hapiot, F.; Tilloy, S.; Monflier, E. Cyclodextrins as Supramolecular Hosts for Organometallic Complexes. Chem. Rev. 2006, 106, 767-781. [CrossRef] [PubMed]

30. Lee, J.U.; Lee, S.S.; Lee, S.; Oh, H.B. Noncovalent Complexes of Cyclodextrin with Small Organic Molecules: Applications and Insights into Host-Guest Interactions in the Gas Phase and Condensed Phase. Molecules 2020, 25, 4048. [CrossRef]

31. Rudolph, S.; Riedel, E.; Henle, T. Studies on the Interaction of the Aromatic Amino Acids Tryptophan, Tyrosine and Phenylalanine as Well as Tryptophan-Containing Dipeptides with Cyclodextrins. Eur. Food Res. Technol. 2018, 244, 1511-1519. [CrossRef]

32. Silion, M.; Fifere, A.; Lungoci, A.L.; Marangoci, N.L.; Ibanescu, S.A.; Zonda, R.; Rotaru, A.; Pinteală, M. Mass Spectrometry as a Complementary Approach for Noncovalently Bound Complexes Based on Cyclodextrins. In Advances in Experimental Medicine and Biology; Woods, A.G., Darie, C.C., Eds.; NLM (Medline); Springer: Berlin/Heidelberg, Germany, 2019; Volume 1140, pp. 685-701. [CrossRef]

33. Braga, S.S.; Gonçalves, I.S.; Pillinger, M.; Ribeiro-Claro, P.; Teixeira-Dias, J.J. Experimental and Theoretical Study of the Interaction of Molybdenocene Dichloride (Cp2MoCl2) with $\beta$-Cyclodextrin. J. Organomet. Chem. 2001, 632, 11-16. [CrossRef]

34. Guo, M.; Song, F.; Liu, Z.; Liu, S. Characterization of Non-Covalent Complexes of Rutin with Cyclodextrins by Electrospray Ionization Tandem Mass Spectrometry. J. Mass Spectrom. 2004, 39, 594-599. [CrossRef]

35. Zhang, D.; Zhang, J.; Jiang, K.; Li, K.; Cong, Y.; Pu, S.; Jin, Y.; Lin, J. Preparation, Characterisation and Antitumour Activity of $\beta$-, $\gamma$ - and HP- $\beta$-Cyclodextrin Inclusion Complexes of Oxaliplatin. Spectrochim. Acta Part A Mol. Biomol. Spectrosc. 2016, 152, 501-508. [CrossRef]

36. Morales, A.; Weber, R.T.; Melendez, E. Spectroscopic and Thermal Characterization of the Host-Guest Interactions between A-, Band $\Gamma$-cyclodextrins and Vanadocene Dichloride. Appl. Organomet. Chem. 2008, 22, 440-450. [CrossRef]

37. Morales, A.; Santana, A.; Althoff, G.; Melendez, E. Host-Guest Interactions between Calixarenes and Cp2NbCl2. J. Organomet. Chem. 2011, 696, 2519-2527. [CrossRef]

38. Turel, I.; Demšar, A.; Košmrlj, J. The Interactions of Titanocene Dihalides with $\alpha$-, $\beta$ - and $\gamma$-Cyclodextrin Host Molecules. J. Incl. Phenom. Macrocycl. Chem. 1999, 35, 595-604. [CrossRef]

39. Bakhtiar, R.; Kaifer, A.E. Mass Spectrometry Studies on the Complexation of Several Organometallic Complexes by $\alpha-$ and $\beta$-Cyclodextrins. Rapid Commun. Mass Spectrom. 1998, 12, 111-114. [CrossRef]

40. Lebrilla, C.B. The Gas-Phase Chemistry of Cyclodextrin Inclusion Complexes. Acc. Chem. Res. 2001, 34, 653-661. [CrossRef]

41. Barylyuk, K.; Balabin, R.M.; Grünstein, D.; Kikkeri, R.; Frankevich, V.; Seeberger, P.H.; Zenobi, R. What Happens to Hydrophobic Interactions during Transfer from the Solution to the Gas Phase? The Case of Electrospray-Based Soft Ionization Methods. J. Am. Soc. Mass Spectrom. 2011, 22, 1167-1177. [CrossRef] [PubMed]

42. Bruni, P.S.; Schürch, S. Fragmentation Mechanisms of Protonated Cyclodextrins in Tandem Mass Spectrometry. Carbohydr. Res. 2021, 504, 108316. [CrossRef] [PubMed]

43. Memboeuf, A.; Jullien, L.; Lartia, R.; Brasme, B.; Gimbert, Y. Tandem Mass Spectrometric Analysis of a Mixture of Isobars Using the Survival Yield Technique. J. Am. Soc. Mass Spectrom. 2011, 22, 1744-1752. [CrossRef]

44. Dossmann, H.; Fontaine, L.; Weisgerber, T.; Bonnet, V.; Monflier, E.; Ponchel, A.; Przybylski, C. First Steps to Rationalize HostGuest Interaction between $\alpha-, \beta-$, and $\gamma$-Cyclodextrin and Divalent First-Row Transition and Post-Transition Metals (Subgroups VIIB, VIIIB, and IIB). Inorg. Chem. 2021, 60, 930-943. [CrossRef] [PubMed]

45. Przybylski, C.; Bonnet, V. Discrimination of Cyclic and Linear Oligosaccharides by Tandem Mass Spectrometry Using CollisionInduced Dissociation (CID), Pulsed-Q-Dissociation (PQD) and the Higherenergy C-Trap Dissociation Modes. Rapid Commun. Mass Spectrom. 2013, 27, 75-87. [CrossRef] [PubMed]

46. Szabó, D.; Schlosser, G.; Vékey, K.; Drahos, L.; Révész, Á. Collision Energies on QTof and Orbitrap Instruments: How to Make Proteomics Measurements Comparable? J. Mass Spectrom. 2021, 56, e4693. [CrossRef] 